\title{
Decadal climate variability and vulnerability of water resources in arid regions of Northwest China
}

\author{
Long Wan $\cdot$ Jun Xia $\cdot$ Si Hong $\cdot$ \\ Hongmei Bu $\cdot$ Like Ning $\cdot$ Junxu Chen
}

Received: 27 October 2013/Accepted: 9 November 2014/Published online: 20 November 2014

(C) Springer-Verlag Berlin Heidelberg 2014

\begin{abstract}
Decadal climate change has evidently posed serious threats and challenges to water resource management across arid regions in China. Thus, vulnerability assessment of water resources has been considered vital to adapt to or cope with the adverse effects of climate change. This paper investigated spatial patterns of decadal climate change and water resources variability in the arid regions of Northwest China based on a GIS analysis. The Budyko hypothesis was used to investigate the climate sensitivity of basin streamflow. A framework was proposed to assess the vulnerability of water resources as a function of exposure, sensitivity, and adaptability. Results indicated that a significant increase in precipitation and water resources (both surface water resources and groundwater recharge) occurred primarily in Xinjiang Province after the 1980s. Water utilization ratio in arid regions was very high, and groundwater abstraction substantially increased as it exceeded the exploitable volume in the Hexi Corridor, the Tuha Basin, and the north of the Tianshan Mountain. Exposure of water resources to drought
\end{abstract}

L. Wan · J. Xia $(\bowtie) \cdot S$. Hong $\cdot$ H. Bu $\cdot$ L. Ning $\cdot$ J. Chen Key Laboratory of Water Cycle and Related Land Surface Processes, Institute of Geographic Sciences and Natural Resources Research, Chinese Academy of Sciences,

Beijing 100101, China

e-mail: xiaj@igsnrr.ac.cn

L. Wan

e-mail: wanlong255@gmail.com

L. Wan $\cdot$ S. Hong $\cdot$ L. Ning $\cdot$ J. Chen

University of Chinese Academy of Sciences,

Beijing 100049, China

J. Xia

State Key Laboratory of Water Resources and Hydropower Engineering Sciences, Wuhan University,

Wuhan 430000, Hubei, China in arid regions decreased from the 1960s to the 2000s. The sensitivity of water resource response to precipitation changes varied between regions. Water resources were more sensitive to precipitation variability in the river basins in the Hexi Corridor and inner Mongolia. In most arid regions in China, water resources were evaluated with low adaptability and high or severe vulnerability in the 2000s. In the future, the precipitation is projected to increase significantly under the RCP2.6, RCP4.5, and RCP8.5 scenarios. Particularly, water vulnerability will be significantly reduced as the precipitation increases in most river basins under the RCP8.5 scenario. Water resources in the rivers in the Qaidam Basin, the Qinhai Lake Basin, the inner Mongolia, and the north of Kunlun Mountain will have low or medium vulnerability in the 2030s and 2050s. However, in the Tuha Basin and Hexi Corridor, vulnerability will remain severe in the 2050s despite the significant increase in precipitation and implementation of water-saving measures. Hence, measures that will facilitate sustainable water resource management must be identified and implemented.

Keywords Vulnerability of water resources - Decadal climate variability $\cdot$ Arid regions of China

\section{Introduction}

Vulnerability is one of the most important topics for various climate impact studies (Watson et al. 1998; Adger et al. 2007; Füssel 2007; Babel and Wahid 2009). According to McNabb (2005), vulnerability assessments of water resources can help evaluate the susceptibility of water systems to potential climate change threats and identify effective adaptation strategies to reduce or mitigate the risk of serious consequences from adverse climate impacts. 
Numerous studies have proposed integrated indexes to evaluate water resource vulnerability (Brown and Matlock 2011). The most commonly used index for evaluating water resource vulnerability was proposed by Falkenmark (1989), who expressed water stresses by using the water use per capita. Likewise, Vörösmartyet al. (2000) developed an index to assess water vulnerability at a global scale. This index was defined as the ratio of water withdrawal to discharge. Sullivan and Huntginford (2009) also introduced an integrated index called climate vulnerability index (CVI) for the assessment of local vulnerability to water-related risks.

Freshwater is a finite and vulnerable resource essential to sustain agriculture, economic development, and the environment (McCaffrey 1992). However, arid regions cover large areas in Northwest China. Regional drought and intensive human activities have caused severe water shortage and ecological deterioration in this region (Xia and Chen 2001; Zhang et al. 2013). More studies have shown that climate variability has presented a decadal change in the arid regions of Northwest China in the past five decades. The surface wetness index (SWI) and Palmer drought severity index (PDSI) showed a negative anomaly over the arid regions during the 1960s and 1970s, but after the 1980s, the increasing precipitation helped relieve the drought. As a result, the SWI and PDSI showed a positive anomaly (Ma and Fu 2006). Decadal climate variability will accelerate or mitigate the vulnerabilities of water systems. With climate change, the evaluation of decadal climate change impacts and vulnerabilities of regional water resources in the arid regions has become increasingly important (Liu 2003).

In this paper, we proposed a framework to assess the vulnerability of water resources to decadal climate change in the arid regions of China. The framework highlights vulnerability assessment based on the evaluation of climate change exposure, sensitivity, and adaptability. Vulnerability assessments were primarily used to understand climate change phenomenon further, as well as to identify mechanisms that can aid water resources in effectively adapting to climate change.

\section{Study area and methods}

Study area and data description

\section{Study area}

The arid regions in Northwest China are located in the north of $35^{\circ} \mathrm{N}$ and west of $110^{\circ} \mathrm{E}$. These regions include the Xinjiang Autonomous Region, the Hexi Corridor of Gansu Province, the area west of the Helan Mountains in inner Mongolia, and the provinces of Ningxia and Qinghai
(Fig. 1). The names of the river basins are shown in Table 1. Within the arid zones, six mountains and some plains are alternately distributed (Feng et al. 2000). The high mountains block the southeast monsoons coming from the Pacific Ocean, thus preventing the southwest monsoon of the Indian Ocean and the air current of the Arctic Ocean from reaching the region (Deng et al. 2006). This condition contributes to the extremely dry condition in the region. The precipitation in the areas ranges $200-800 \mathrm{~mm}$ in the mountain zones, $50-200 \mathrm{~mm}$ in the middle section, and $20-50 \mathrm{~mm}$ in the desert zone of the lower reaches. Given these situations and conditions, water shortage in these regions has become severe. This situation creates an unfavorable scenario because water is considered indispensable for economic and agricultural development, as well as in maintaining ecological balance within the regions (Bao and Fang 2007).

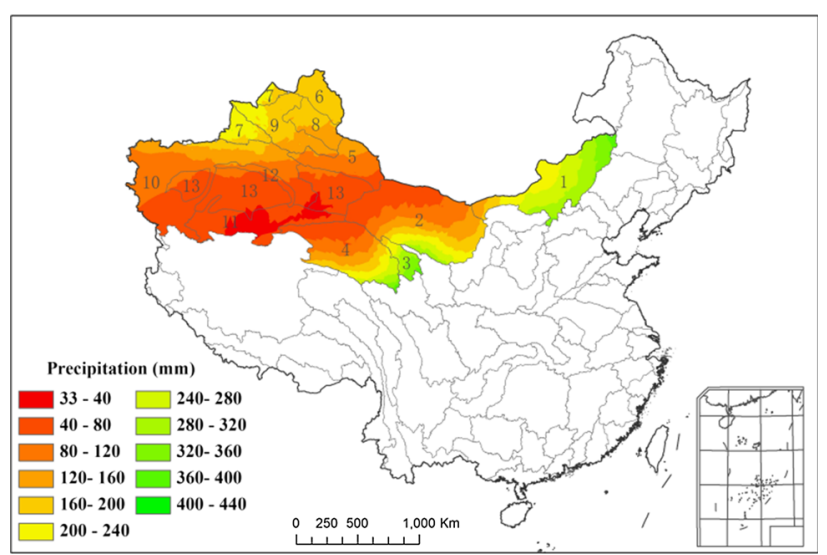

Fig. 1 Location and distribution of annual precipitation in the study area

Table 1 Name of all river basins in the study area

\begin{tabular}{ll}
\hline Number & River basins \\
\hline 1 & Inland rivers in the Inner Mongolia \\
2 & Hexi Corridor \\
3 & Rivers in Qinghai Lake Basin \\
4 & Rivers in Qaidam Basin \\
5 & Rivers in Tuha Basin \\
6 & Rivers in the south of Aertaishan Mountain \\
7 & Rivers in the Central Asia \\
8 & Gurbantunggut Desert \\
9 & Rivers in the north of Tianshan Mountain \\
10 & Headstreams of Tarim River \\
11 & Rivers in the north of Kunlun Mountain \\
12 & Mainstreams of Tarim River \\
13 & Taklimakan Desert \\
\hline
\end{tabular}

Each number in Table 1 represents the same river basin as shown Fig. 1 


\section{Data description}

Daily precipitation, temperature data, and other meteorological data in more than 160 stations were obtained from the China Meteorological Administration. The amount of water resources, water consumption, and ecological water requirement data for each river basin were mainly derived from the water resources investigation in Northwest China (Dong et al. 2006). The surface water resource and the groundwater recharge estimation processes were also illustrated in the book of water resources investigation in Northwest China (Dong et al. 2006).

Future climate was analyzed by the China Meteorological Administration based on the CMIP5 multi-model dataset (coupled model intercomparison project phase 5). Representative concentration pathways RCP2.6, RCP4.5, and RCP8.5 emission scenarios were included in the CMIP5 for climate projection.

Methods

Framework of vulnerability assessment of water resources in arid regions

Intergovernmental panel on climate change fourth assessment report (2007) defined vulnerability as the degree to which a system is susceptible to, and unable to cope with, the adverse effects of climate change. These adverse effects include climate variability and extreme conditions. Vulnerability is a function of the character, magnitude, and rate of climate change and variation to which a system is exposed, its sensitivity, and its adaptive capacity.

Most of the climate impact studies focus on vulnerability and the related concepts of exposure, sensitivity, and adaptability (Heltberg and Bonch-Osmolovskiy 2011; Fellmann and Lankoski 2012). Factors influencing climate vulnerability include (Cui et al. 2010):

1. Exposure The degree of climate stress, such as drought upon water resources and people.

2. Sensitivity The degree to which a system will respond, either positively or negatively, to a change in climate.

3. Adaptability The capacity of a system to adjust in response to actual or expected climate stimuli, their effects, or impacts.

Based on the framework in Fig. 2, the vulnerability of water resources can be expressed as a function of all the three components of exposure, sensitivity, and adaptability, as shown in Eq. (1).

Vulnerability $=($ Exposure $\times$ Sensitivity $) /$ Adaptability

This equation indicates that as the sensitivity and exposure to climate change increase, vulnerability increases under the same condition, which implies that vulnerability is decreased by adaptability (Cui et al. 2010).

In the arid regions, water resource systems have been characterized by severe drought conditions, extremely high degree of water exploitation, and continuous ecological deterioration. In this study, the selection of vulnerability indicators directly reflected the characteristics of the local
Fig. 2 Framework of vulnerability assessment of water resources in arid regions in Northwest China

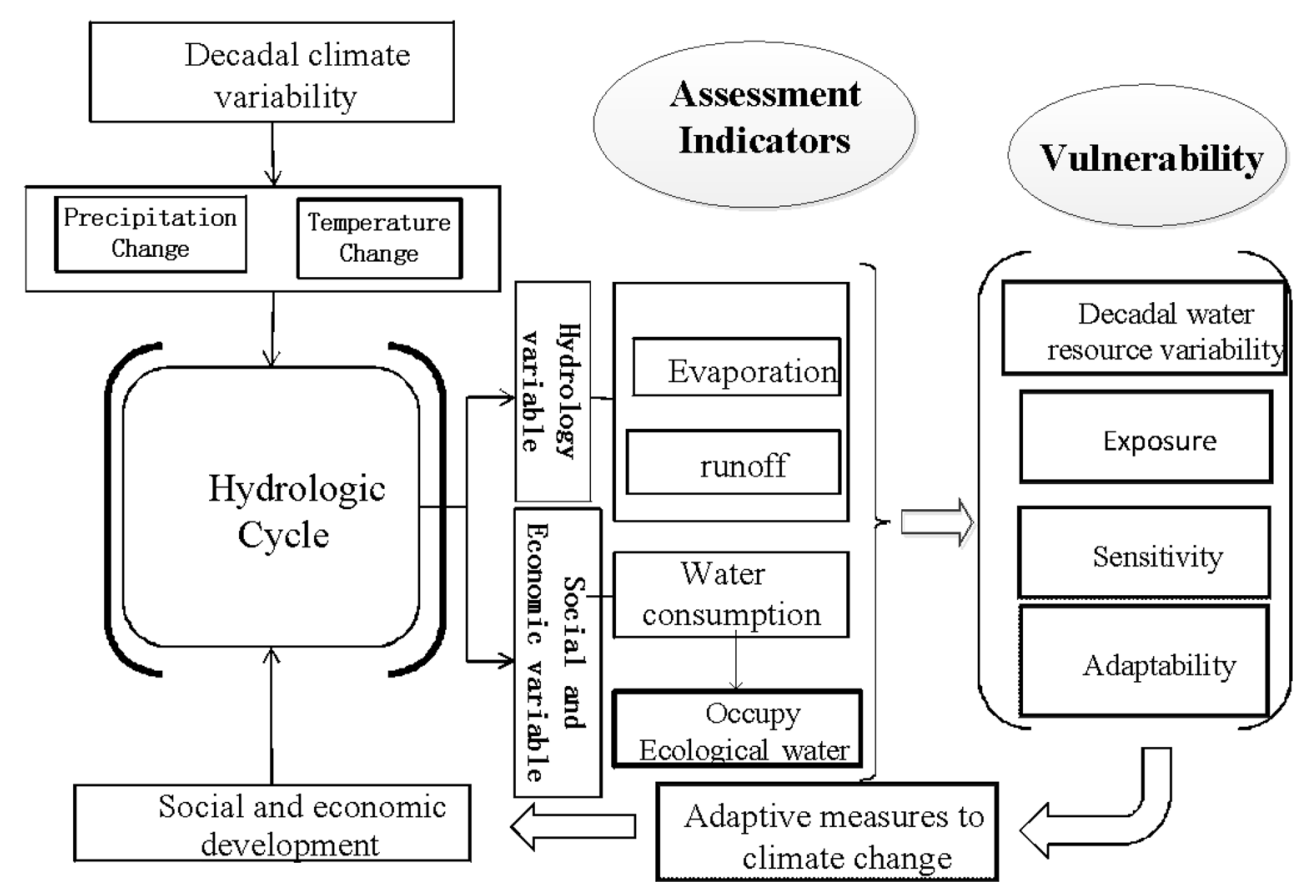


Table 2 Indicators of exposure, sensitivity and adaptability assessment

\begin{tabular}{ll}
\hline & Indicators \\
\hline $\begin{array}{l}\text { Exposure } \\
\text { Sensitivity }\end{array}$ & $\begin{array}{l}\text { Aridity anomaly index } \\
\text { Sensitivity of water resources change response to } \\
\text { precipitation change } \\
\text { Adaptability } \\
\end{array}$ \\
& $\begin{array}{l}\text { Exploitation ratio of available water resources }(r) \\
\text { Available water resources per capita (WP) } \\
\text { Ratio of ecological water use to basic ecological water } \\
\text { requirements (ER) }\end{array}$ \\
\hline
\end{tabular}

water system, as presented in Table 2 . The aridity anomaly index was used to assess the exposure of water resources to climate change. Three integrated indicators were chosen to assess the adaptability of water resources, including exploitation ratio of available water resources (r), available water resources per capita (WP), and the ratio of ecological water use to basic ecological water requirements (ER)

$$
\begin{array}{r}
r=\frac{W_{\text {use }}}{W_{\text {available }}}=\frac{W_{\text {use }}}{W_{\text {total }}-W_{\text {eco }}} \\
\mathrm{WP}=\frac{W_{\text {available }}}{\text { population }}=\frac{W_{\text {total }}-W_{\text {eco }}}{\text { population }} \\
\mathrm{ER}=\frac{W_{\text {eco }}}{W_{\text {eco,min }}} .
\end{array}
$$

Equation (2) shows that greater values of WP and ER indicate greater adaptability, whereas a greater value of $r$ indicates low adaptability. Thus, we propose that adaptability is directly proportional to the ER and WP, but inversely proportional to $r$, as presented in Eq. (3)

Adaptability $=\frac{W_{\text {eco }}}{W_{\text {eco,min }}} \times\left(\frac{\frac{W_{\text {avalable }}}{\text { population }}}{1,000}\right) / r$

where $r$ is the exploitation ratio of available water resources, $W_{\text {total }}$ is the total water resources in the region, and $W_{\text {availble }}$ denotes the available water resources. We suppose that $1,000 \mathrm{~m}^{3}$ of available water resources per capita is the threshold of high water stress in Northwest China. WP/1,000 values were limited within the range of $0-1$, such that if WP/1,000 $>1$, then WP/1,000 $=1 . W_{\text {use }}$ refers to the total agricultural, industrial, and domestic water use; $W_{\text {eco }}$ is the ecological water use amount; and $W_{\text {eco,min }}$ is the minimum ecological water requirements.

To standardize the vulnerability values, an exponential function was proposed to normalize the values (Fig. 3). Thus, values can be located within the range of $0-1$. For this research, the vulnerability was calculated by using the following formula:

Vulnerability $=e^{\left(-\frac{k}{\text { Sensitivive } \times \text { Exposure }}\right)}$

where $k$ is the parameter.

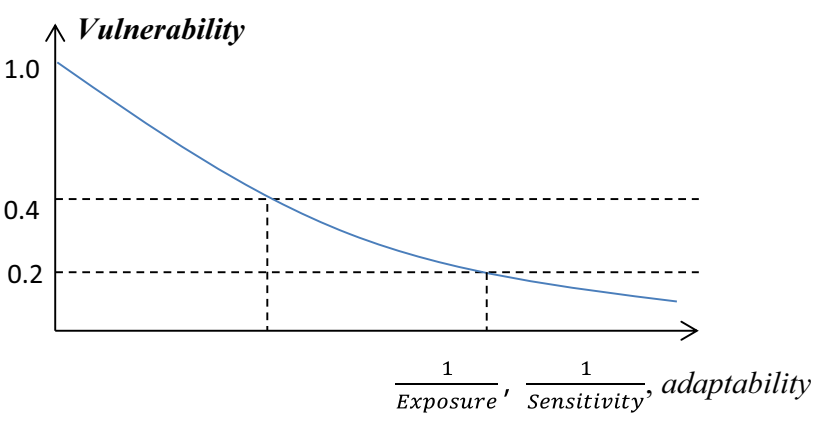

Fig. 3 Exponential relationships between vulnerability and exposure, sensitivity and adaptability

Table 3 Classification of vulnerability values

\begin{tabular}{ll}
\hline Vulnerability & Classification \\
\hline Low vulnerability & $0<$ vulnerability $\leq 0.2$ \\
Medium vulnerability & $0.2<$ vulnerability $\leq 0.4$ \\
Medium-high vulnerability & $0.4<$ vulnerability $\leq 0.6$ \\
High vulnerability & $0.6<$ vulnerability $\leq 0.8$ \\
Severe vulnerability & $0.8<$ vulnerability $\leq 1.0$ \\
\hline
\end{tabular}

With the assumption that $r=0.4, \mathrm{WP}=1, \mathrm{ER}=1$, sensitivity $=1$, and exposure $=0.1$, the vulnerability value is 0.4 . Based on the vulnerability classification of Vörösmarty et al. (2000), the value 0.4 is considered high. Hence, a high degree of vulnerability exists. Meanwhile, the computation for $k$ was equal to 0.036 . The classification of vulnerability values is shown in Table 3 .

\section{Evaluation of water resource sensitivity to climate change}

Hydrologic sensitivity can be defined as the percentage change in mean annual streamflow occurring in response to a change in mean annual precipitation $(P)$ and potential evapotranspiration $\left(E_{0}\right)$ (Ma et al. 2008; Donohue et al. 2011). The water balance for a catchment can be written as:

$\bar{R}=\bar{P}-\bar{E}+\Delta S$

where $P$ is precipitation, $E$ is actual evapotranspiration, $Q$ is streamflow, and $\Delta S$ is the change in catchment water storage. Over a long period of time, $\Delta S$ is assumed to be zero.

Mean annual actual evapotranspiration can be estimated based on precipitation and potential evapotranspiration. Budyko and Miller (1974) developed a framework for estimating actual evapotranspiration based on dryness index. Based on this framework, Fu (1981)combined dimensional analysis with mathematical reasoning and developed analytical solutions for mean annual actual evapotranspiration, as shown in Eq. (6). 
$\frac{E}{P}=1+\frac{E_{0}}{P}-\left[1+\left(\frac{E_{0}}{P}\right)^{w}\right]^{1 / w}$,

where $\omega$ is a model parameter related to vegetation type, soil hydraulic property, and topography.

Changes in mean annual precipitation and potential evapotranspiration can result in changes in annual runoff, and the relationship can be approximated as:

$\Delta Q=\frac{\partial Q}{\partial P} \Delta P+\frac{\partial Q}{\partial E} \Delta E_{0}$,

where $\Delta P, \Delta E_{0}$ are changes in precipitation and potential evapotranspiration, respectively; and

$\frac{\partial Q}{\partial P}=P^{(\omega-1)}\left(E_{0}^{\omega}+P^{\omega}\right)^{\frac{1}{\omega}-1}$

as obtained from Eqs. (6) and (7).

\section{Results}

Decadal precipitation change and water resources variability

The mean annual precipitation for arid regions was based on the average of more than 160 meteorological stations in the Northwest China. Results indicated that in 2000s, the mean precipitation is about $189 \mathrm{~mm}$ in our study area. The total natural surface water resources is about $1052 \times 10^{8} \mathrm{~m}^{3}$, and total ground water recharge is about $105 \times 10^{8} \mathrm{~m}^{3}$, while the water resources exploitation reached more than $600 \times 10^{8} \mathrm{~m}^{3} / \mathrm{a}$ in our study area.

Precipitation and total water resources in the arid regions of Northwest China decreased from 1956 to the 1970s. Interestingly, wet conditions started to increase after the 1980s (Fig. 4). From the 1980s to 2000s, precipitation increased by more than $10 \%$, and surface water resources increased by more than $100 \times 10^{8} \mathrm{~m}^{3}$. Groundwater recharge is also an important process for sustainable water management. From the 1980s to 2000s, the average annual groundwater recharge in the arid regions increased about $6 \%$ in the study area.

The precipitation anomalies were derived for each decade from the 1960s to the 2000s. Figure 5 shows the spatial patterns of decadal precipitation anomalies from the 1960 s to the 2000s. Results show that precipitation anomalies varied in the regions along periods of time. In the 1960 s to 1970 s, precipitation anomalies were negative in most parts of the arid regions. As the 1980s unfolded, Southern Xinjiang Province exhibited positive precipitation anomalies, whereas the other regions remained negative. Only in the 1990 s to 2000 s were positive anomalies observed in most of the regions.
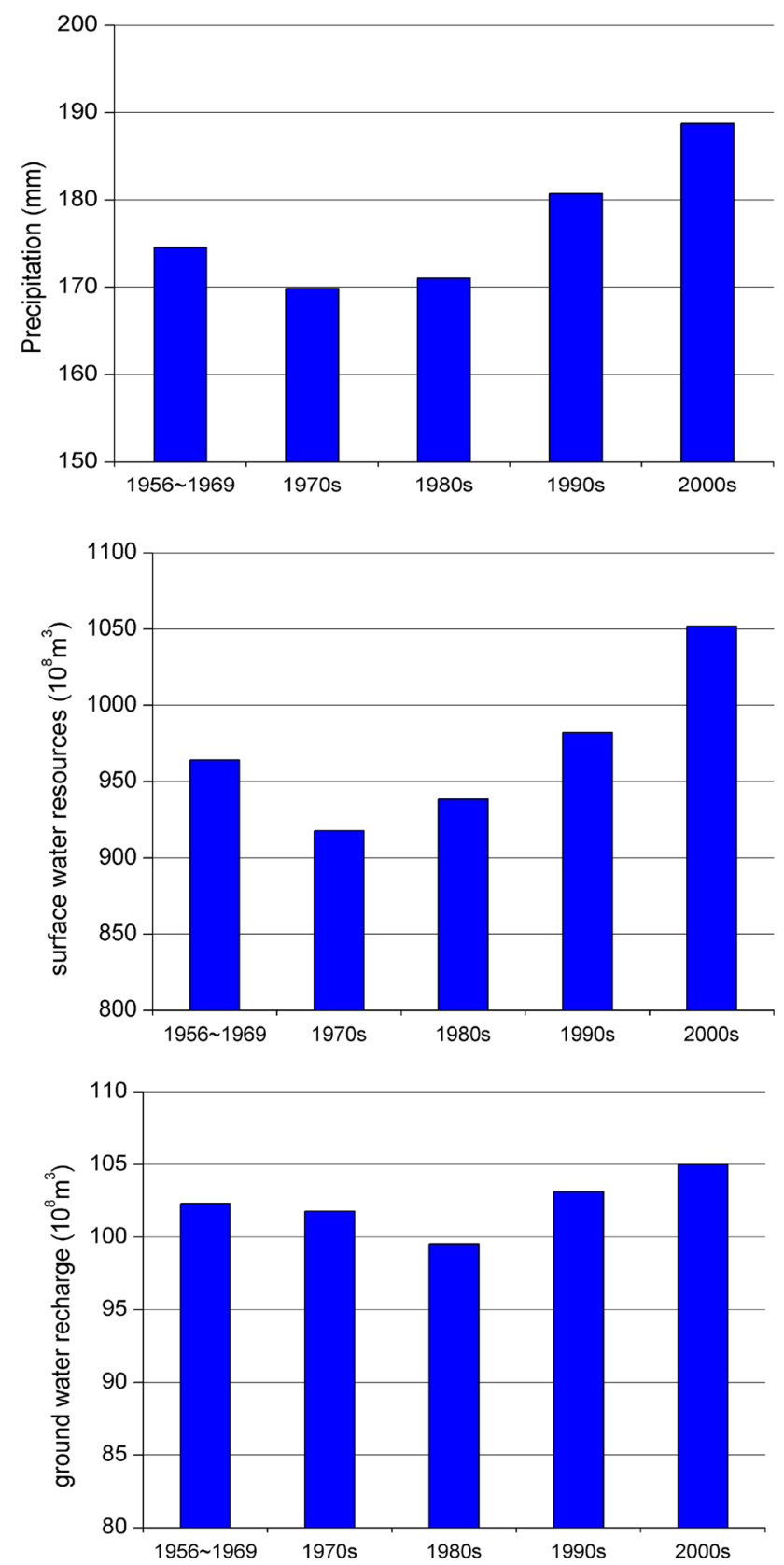

Fig. 4 Decadal precipitation change and water resource variability in the arid regions in Northwest China

The amount of decadal surface water resources in different river basins were also altered by the changed precipitation patterns, as shown in Fig. 6. In Xinjiang Province, surface water resources in most river basins were low in the 1956 to 1970s. However, such resources were observed to increase significantly in this area and in the Qaidam Basin in the 1980s to 2000s. Surface water resources in the rivers of the Hexi Corridor and the Inner Mongolia slightly changed from the 1950s to the 2000s.

Population in the arid regions of Northwest China has increased dramatically in the past. For instance, from 1950 

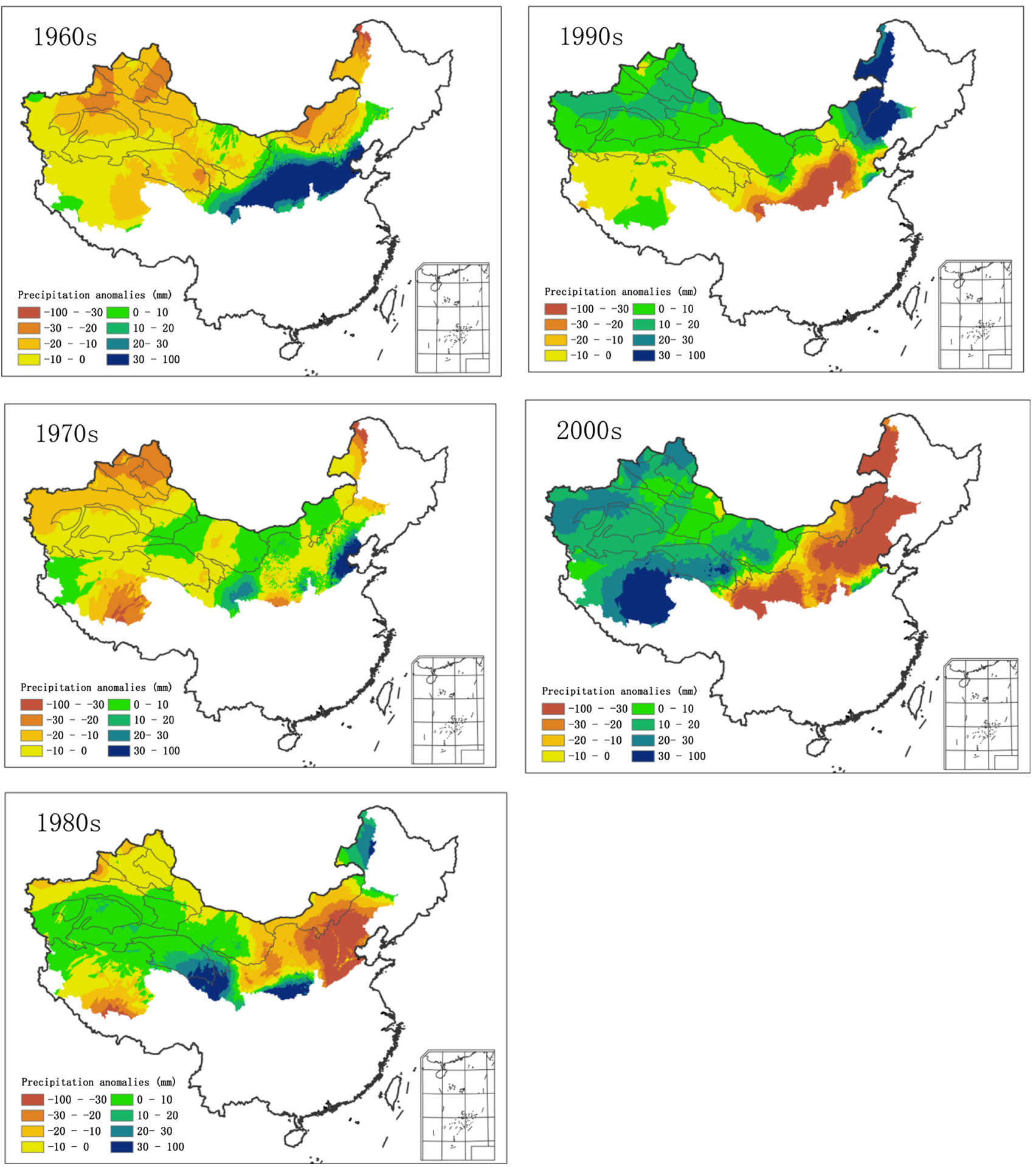

Fig. 5 Spatial patterns of decadal precipitation anomalies in the arid regions of Northwest China

to 2010, population has a continued to rise from $444 \times 10^{4}$ people to $2,181 \times 10^{4}$ people in Xinjiang Province (Mansur and Rahman 2007) (Fig. 7). The population has increased by about $290 \times 10^{4}$ people per decade. Consequently, the need for water resources has significantly increased as a result of social and economic development, coupled with the rapid population growth in the arid regions of Northwest China since the 1950s. The water consumption even exceeded the total amount of water resources in the 2000s. Agriculture is the largest consumer 

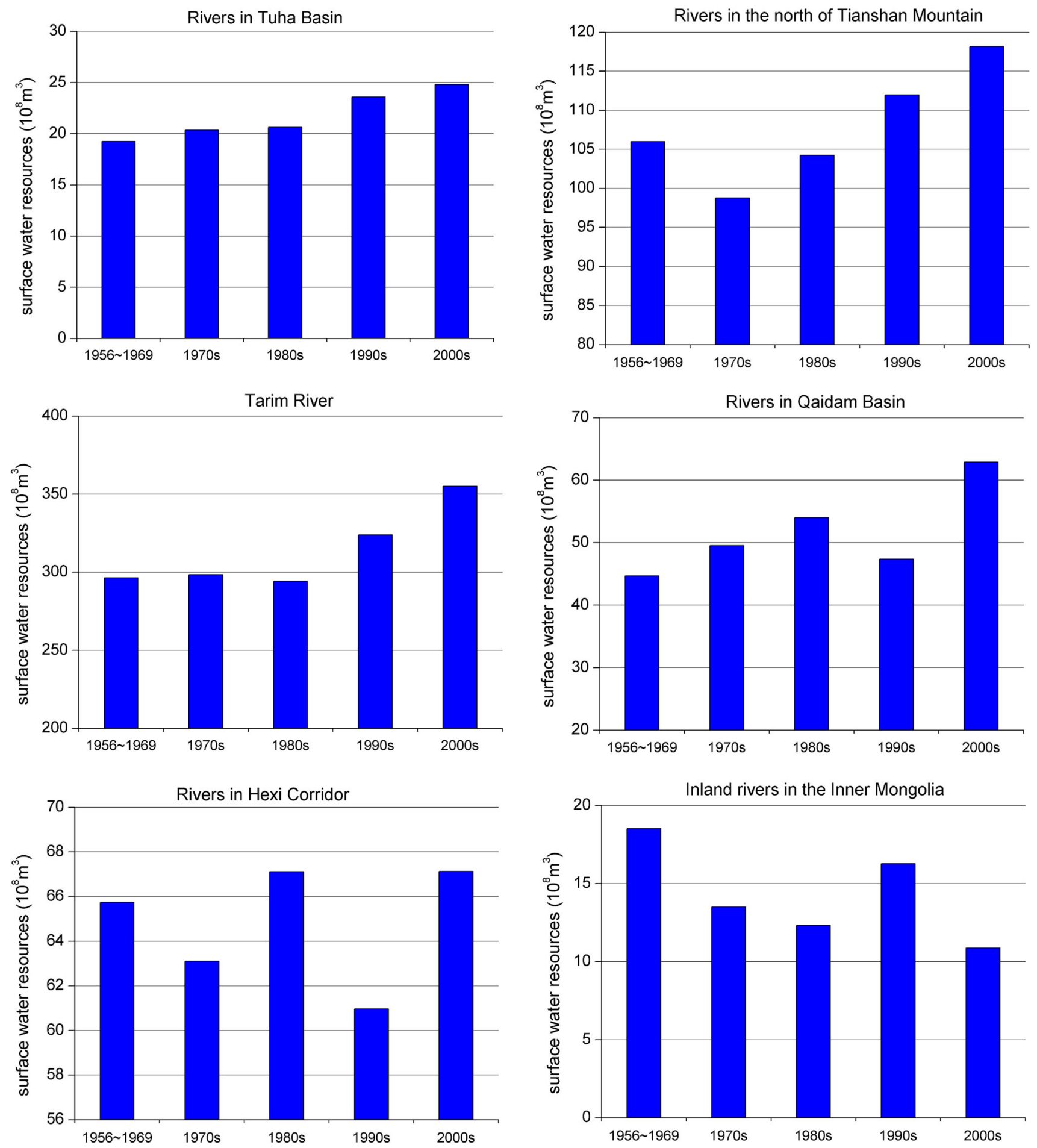

Fig. 6 Decadal surface water resources in different river basins in the arid regions of Northwest China

of freshwater resources at more than $80 \%$ in the arid regions. In many river basins, the water consumption has been close to or even higher than the total water resources (Table 4). This condition can be observed in the rivers in Hexi Corridor, Tarim Basin, and in the north of the Tianshan Mountain (Wang and Cheng 2000).
With increasing demand, larger volumes of water were abstracted from groundwater resources. As presented in Fig. 8, groundwater exploitation has increased dramatically in the arid regions of Northwest China since the 1980s. The total groundwater use in the arid regions was only less than $40 \times 10^{8} \mathrm{~m}^{3}$, but has increased to more than 


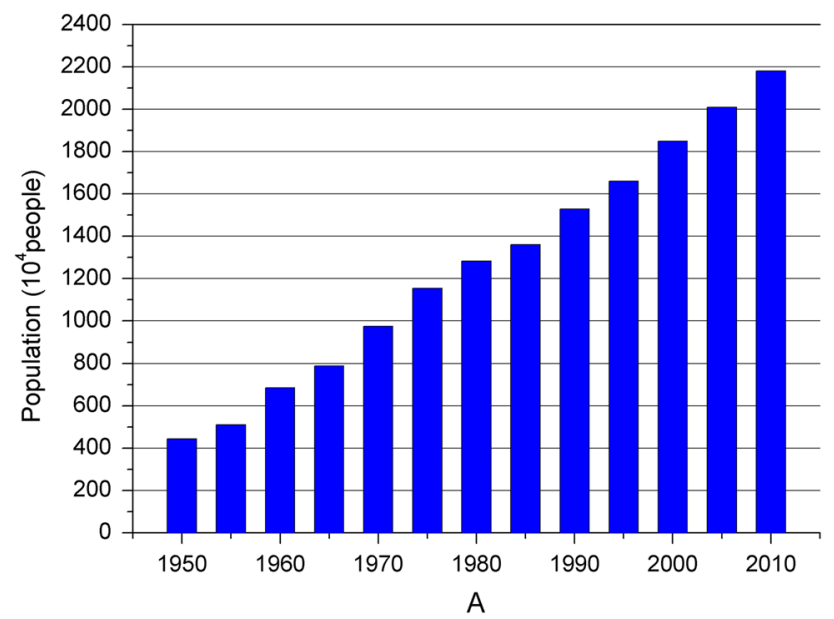

Fig. 7 Population growth in Xijiang Province of Northwest China from 1950-2010

$100 \times 10^{8} \mathrm{~m}^{3}$ in the 2000s. In some rivers, the average annual groundwater abstraction is more than average annual groundwater recharge. In the 1950s, the groundwater abstraction was less than $2 \times 10^{8} \mathrm{~m}^{3}$ in Shiyang River Basin. However, the groundwater abstraction has increased to more than $10 \times 10^{8} \mathrm{~m}^{3}$ in the $2000 \mathrm{~s}$, far exceeding the exploitable volume. In 2008 , the groundwater abstraction in many river basins has exceeded or was close to the exploitable volume in such river basins as those in the Tuha Basin, the Hexi Corridor, and the north of the Tianshan Mountain. Thus, the over-exploitation of groundwater resources must be regulated to mitigate the water stresses in the arid regions.

Vulnerability assessment of water resources in the arid regions of Northwest China

\section{Exposure of water resources}

The exposure of water resources in the arid regions is mainly determined by the varying degree of the drought. In this study, the exposure of water resources was evaluated using the anomaly of aridity because the anomaly of aridity from a normal value can signify the water shortage from a

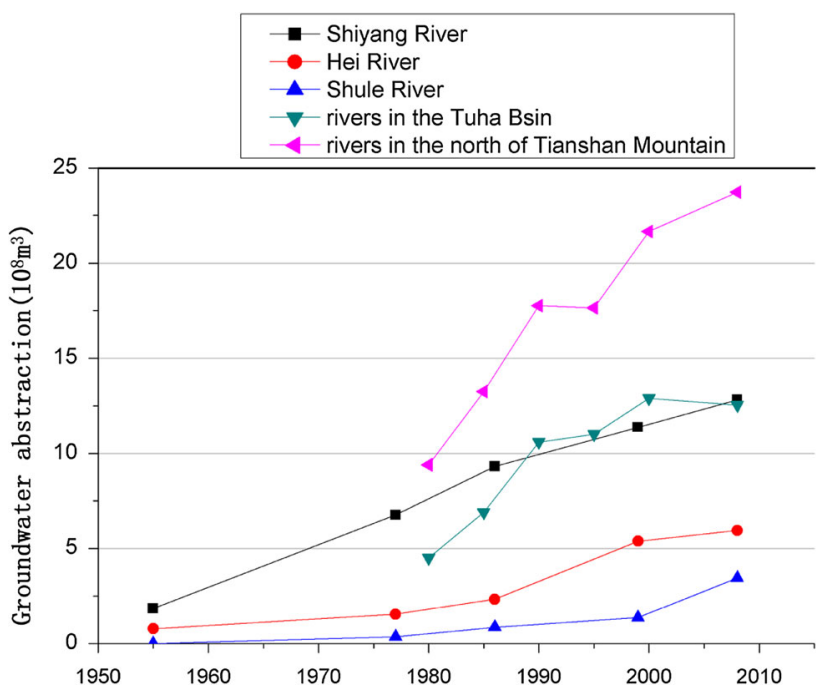

Fig. 8 Groundwater abstraction increase in some rivers in the arid regions of Northwest China

long-term climatic value. The aridity anomaly index (AI) is calculated using the formula:

$\mathrm{AI}=\left(\frac{\mathrm{ET}}{P}-\frac{\mathrm{ET}_{0}}{P_{0}}\right) / \frac{\mathrm{ET}_{0}}{P_{0}}$.

To limit the exposure value to a range between 0 and 1 , the exposure is defined as:

$\left\{\begin{array}{ll}\text { Exposure }=0.05 & \text { AI }<0.05 \\ \text { Exposure }=\text { AI } & \text { AI }>0.05\end{array}\right.$,

where $\mathrm{ET}_{0}$ is the mean annual reference evapotranspiration for the 1960s to 2010s, $P_{0}$ is the mean annual precipitation for the 1960s to 2010s, ET is the mean annual reference evapotranspiration for each decade, and $P$ is the mean annual precipitation for each decade.

The corresponding departures of the aridity values from the normal value were obtained for each decade from the 1960s to 2000s (Fig. 9).

From the 1960 s to 1980 s, major parts of the arid region in Northwest China were under severe drought conditions because of deficient precipitation. The most severe exposure to drought was primarily located in Xinjiang Province. Rivers in the region of the Hexi

Table 4 Water use ratio in some rivers of Northwest China in 2008

\begin{tabular}{lllllll}
\hline River basins & $\begin{array}{l}\text { Domestic water } \\
\text { use }\left(10^{8} \mathrm{~m}^{3}\right)\end{array}$ & $\begin{array}{l}\text { Industrial water } \\
\text { use }\left(10^{8} \mathrm{~m}^{3}\right)\end{array}$ & $\begin{array}{l}\text { Agricultural water } \\
\text { use }\left(10^{8} \mathrm{~m}^{3}\right)\end{array}$ & $\begin{array}{l}\text { Ecological water } \\
\text { use }\left(10^{8} \mathrm{~m}^{3}\right)\end{array}$ & $\begin{array}{l}\text { Total water use } \\
\left(10^{8} \mathrm{~m}^{3}\right)\end{array}$ & $\begin{array}{l}\text { Total water } \\
\text { resources }\left(10^{8} \mathrm{~m}^{3}\right)\end{array}$ \\
\hline $\begin{array}{l}\text { Hexi Corridor } \\
\begin{array}{c}\text { North of the } \\
\text { Tianshan Mt. }\end{array}\end{array}$ & 0.67 & 4.04 & 71.82 & 7.41 & 85.94 & 71.36 \\
$\begin{array}{l}\text { Tarim Basin } \\
\text { Tarim }\end{array}$ & 4.14 & 1.04 & 22.27 & 0.74 & 24.7 & 25.07 \\
\end{tabular}



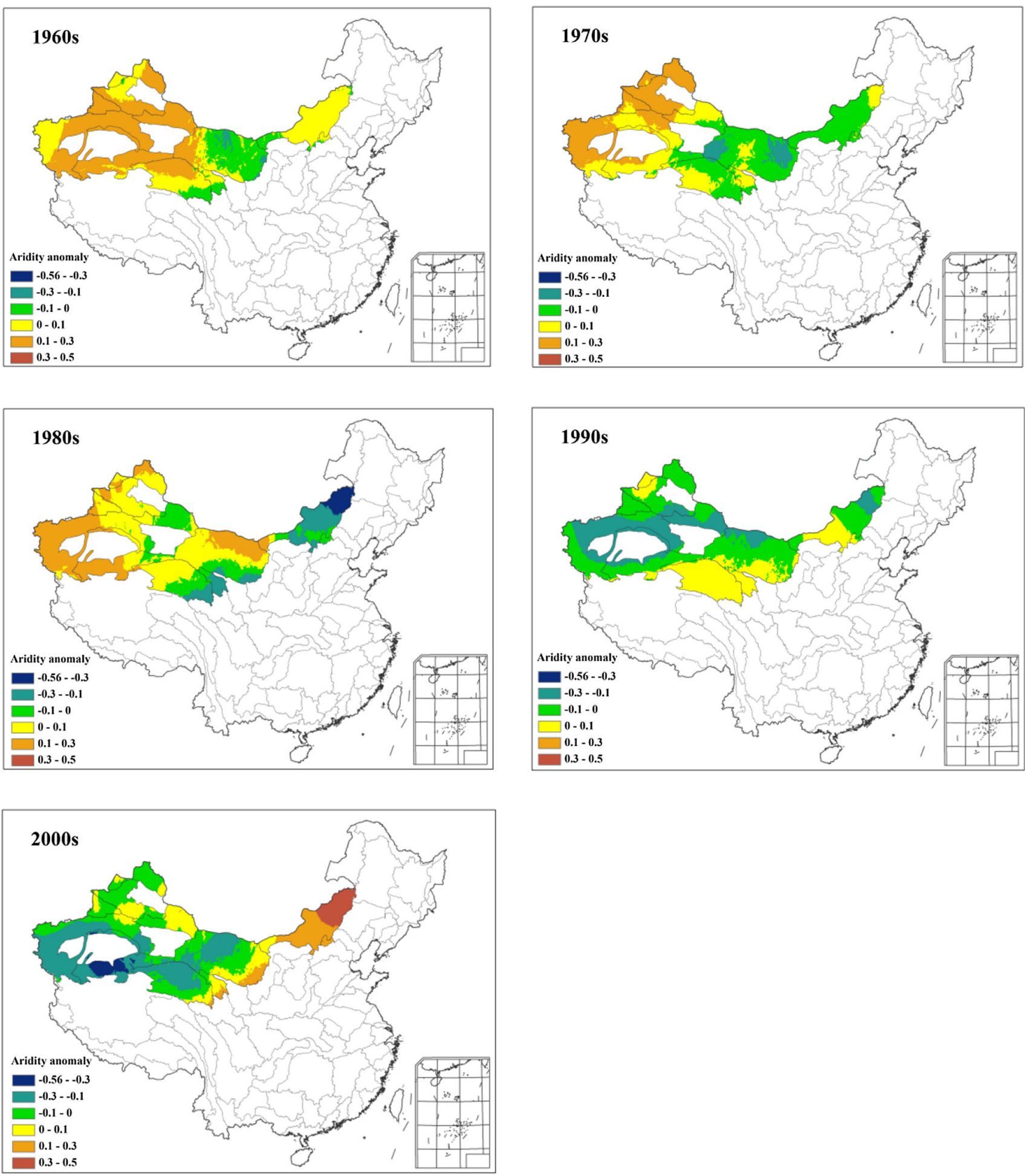

Fig. 9 Aridity anomaly for each decade from the 1960s to 2000s in the arid regions of Northwest China

Corridor and the Inner Mongolia showed a positive anomaly of aridity.

During the 1990s and 2000s, the increase in precipitation has evidently improved the drought condition. Thus, the potential for drought-related exposure was reduced. Most parts of Xinjiang Province and the Hexi Corridor were observed to have a negative aridity anomaly, whereas Inner Mongolia showed an increasing trend of aridity. 
Sensitivity of water resources to climate change

Climate change will affect many aspects of the hydrological cycle in the arid regions of Northwest China (Arnell 1999). The changes in precipitation patterns will significantly affect the changes in the available amount of water resources. As a result, these conditions will significantly affect the vulnerability of water resources. Thus, evaluating the sensitivity of water resource response to precipitation change was deemed important to assess vulnerability to the effects of climate change.

We examine the sensitivity of water resource response to precipitation variability in the arid regions of Northwest China based on Fu's formulation of the Budyko framework. The parameters in Eq. (8) are calculated and shown in Table 4.

Sensitivity of water resource response to precipitation changes was evaluated as presented in Fig. 10. Results indicated that every $10 \%$ change in precipitation can result in approximately 10-20\% change in water resources. Water resource is more sensitive to precipitation variability in the river basins in Hexi Corridor and Inner Mongolia. A $10 \%$ change in precipitation will result in a $15-20 \%$ change in water resources in the two river basins, whereas changes in water resources only ranged $10-15 \%$ in other inland river basins in response to $10 \%$ of precipitation change.

\section{Adaptability and vulnerability assessment of water} resources under climate change

Considerable attention has been devoted to the characteristics of systems that influence the propensity or capability of water resources to adapt (Smit and Pilifosova 2003). Adaptability assessment and enhancement of adaptive capacity of water resources is essential for reducing regional vulnerabilities. Moreover, adaptability assessment is also crucial to identify effective adaptive measures for integrated management of water resources (Smit and Wandel 2006).

In the arid regions of Northwest China, the adaptability of water resources was evaluated by using Eq. (3). Vulnerability of water resources was assessed based on exposure, sensitivity, and adaptability using Eq. (4).

Figure 11 shows that water resources in most arid regions of Northwest China were characterized by low adaptability in the 2000s. The rivers in Tarim Basin, Tuha Basin, Hexi Corridor, and north of Tianshan Mountain had the lowest adaptability. As the arable land expanded and population rapidly increased within these areas, water consumption increased significantly and exceeded the amount of available water resources. Thus, the water exploitation ratio has gone beyond $100 \%$. However, water

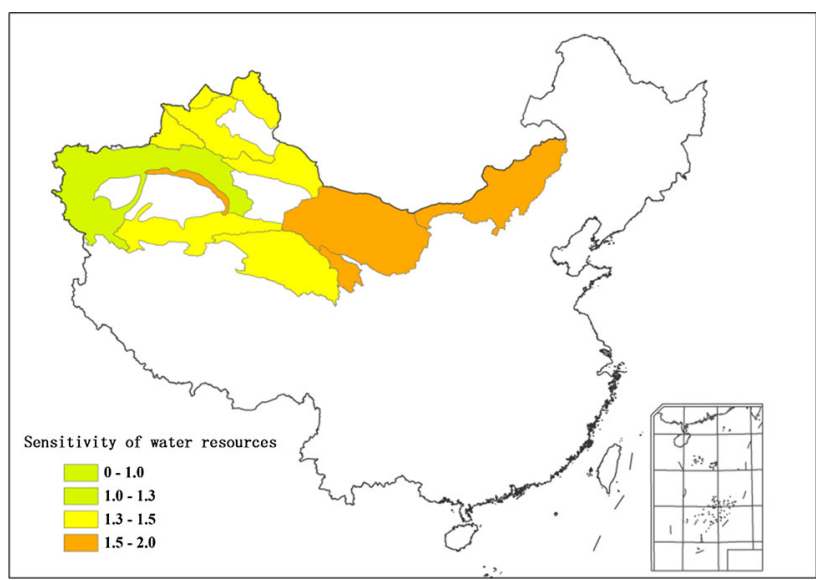

Fig. 10 Sensitivity of water resources response to precipitation changes in the arid regions of Northwest China

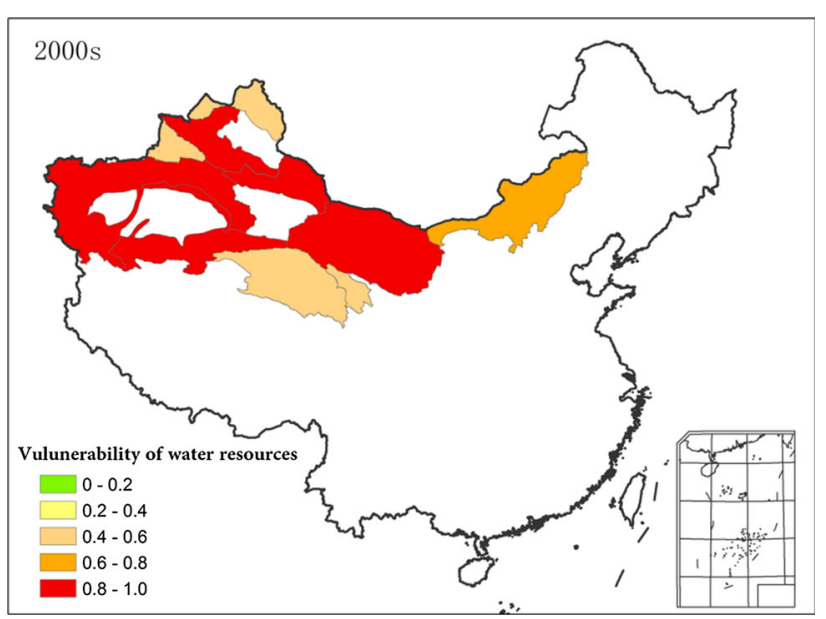

Fig. 11 Vulnerability of water resources in the 2000s in the arid regions of Northwest China

consumption for sustaining the ecological balance in this region was minimal in the 2000 s, accounting for less than $10 \%$ of the basic ecological water requirements. This condition means that the ecology and environment consistently deteriorated in the middle and the lower reaches of the river basins. Owing to the low adaptability of water resources, the evaluated vulnerability values were more than 0.9 , indicating severe vulnerability.

Medium adaptability was observed in the rivers in Central Asia, Inner Mongolia, and Qaidam Basin in the 2000s. Water exploitation ratio in these regions ranged $40-60 \%$. Coupled with the exposure and sensitivity, vulnerability assessment indicated that water resources in these river basins had high vulnerability. Water resources in identified river basins were also insufficient to meet the agricultural, industrial, and ecological water requirements. Thus, the protection of water resources against climate change requires considerable attention. 
Prediction of water resource vulnerability under different future scenarios

The CMIP5 models simulate the future climate conditions in Northwest China. In this paper, precipitation is projected to have a significant increase under the RCP2.6, RCP4.5, and the RCP8.5 scenarios. The highest precipitation is projected under the RCP8.5 scenario compared with the other two scenarios, specifically in the 2050s. According to the simulation, the average precipitation in the arid regions of Northwest China will increase by $13.8 \%$ (RCP2.6), $17.5 \%$ (RCP4.5), and $18.3 \%$ (RCP8.5) in the 2030s compared with the 2000s. In the 2050s, the value is projected to increase by $17.4 \%$ (RCP2.6), $21.2 \%$ (RCP4.5), and $26.5 \%(\mathrm{RCP} 8.5)$ as presented in Fig. 12. The most significant increase in precipitation is distributed within the rivers in Qaidam Basin and in the north of the Kunlun Mountain (Fig. 13). In particular, precipitation in these two river basins will increase by more than $20 \%$ in the 2030 s and by $50 \%$ in the 2050s. However, the precipitation in the river basins in Central Asia and the north of the Tianshan Mountain will only increase by approximately $1 \%$ in the 2030 s and by $4 \%$ in the 2050s. In this work, the RCP8.5 scenario was chosen to analyze whether the projected precipitation increase can mitigate the vulnerability of water resources in Northwest China.

To consider both climate change and changes in the social condition, two scenarios in the 2030s and 2050s were used to assess the water vulnerability in the arid regions of Northwest China.
Fig. 12 Decadal precipitation increases ratio in future than in the 2000s under the RCP2.6, $\mathrm{RCP} 4.5$, and RCP8.5 scenarios
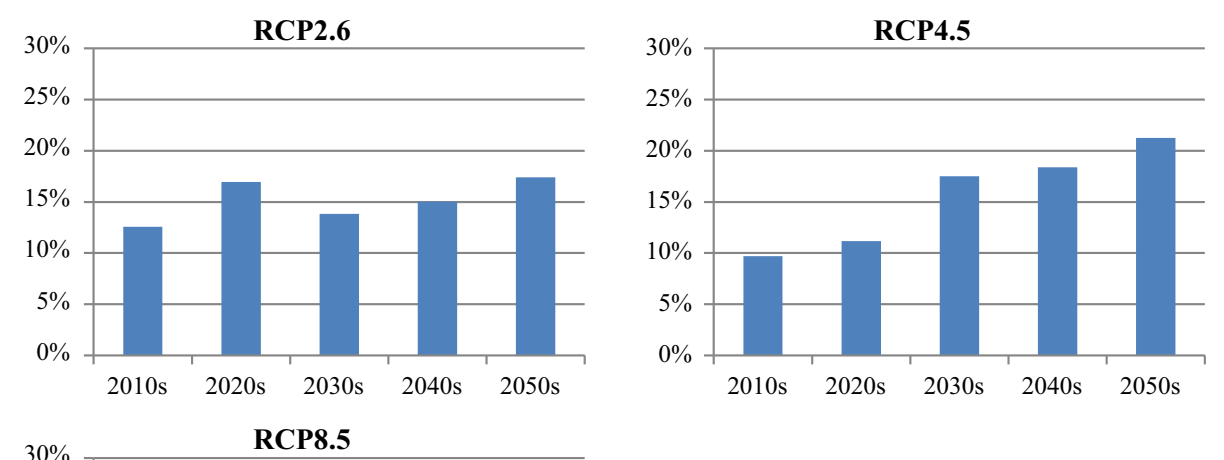
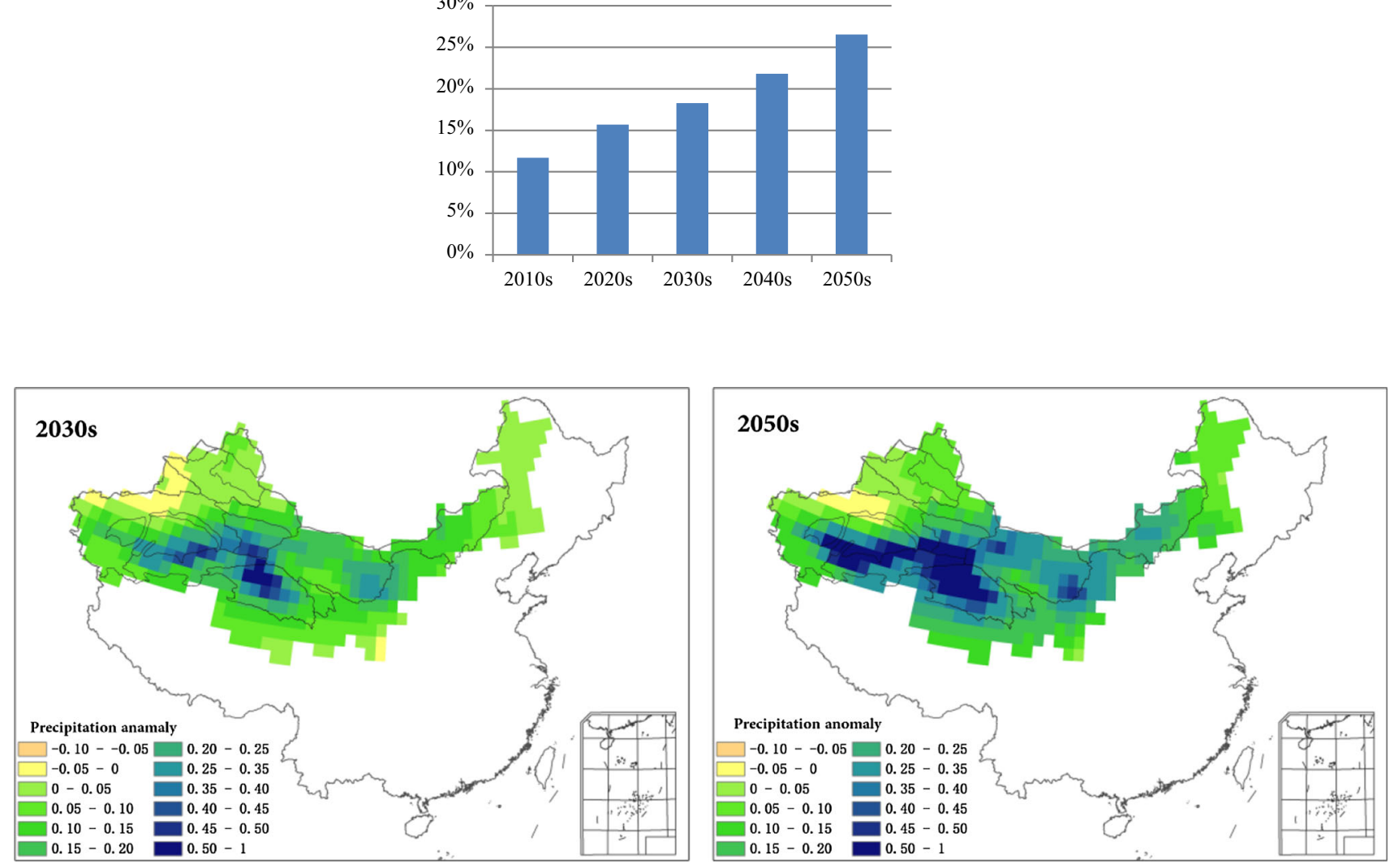

Fig. 13 Spatial patterns of future precipitation increase under the RCP8.5 scenario compared with the decade 2000s 

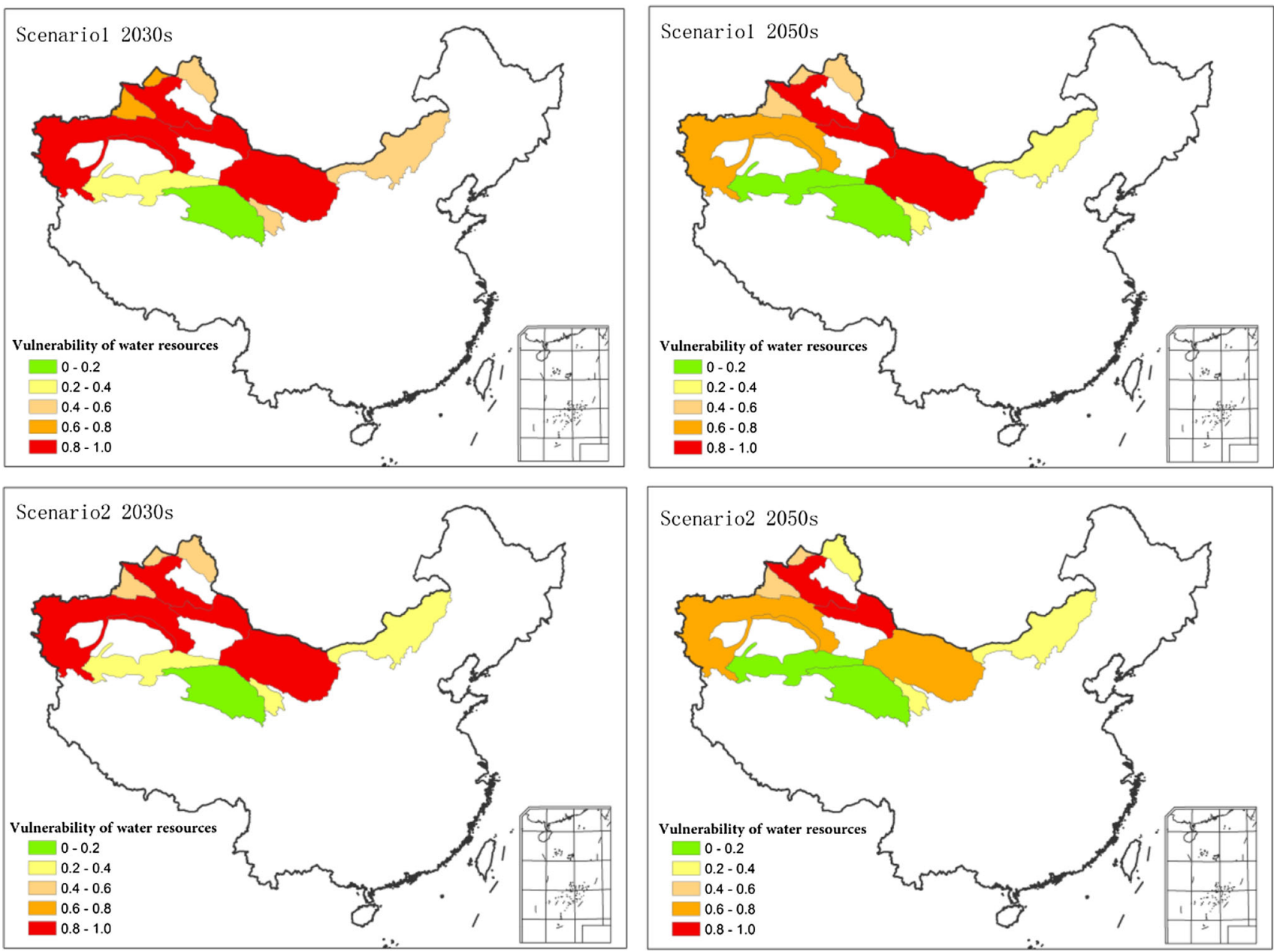

Fig. 14 Future vulnerability of water resources in the arid regions in Scenario 1 and Scenario 2

Scenario 1 In the RCP8.5 scenario, the precipitation will increase by $18.3 \%$ in the $2030 \mathrm{~s}$ and by $26.5 \%$ in the 2050s. According to the Water Demand Prediction in Northwest China (Xiao et al. 2011), the population will increase by $13 \%$ in the 2030s and by $20 \%$ in the 2050s. If we have less water-saving appliances or practice, the estimated water consumption will increase by $15 \%$ in the 2030s and by $22 \%$ in the 2050s.

Scenario 2 Decadal precipitation will continue to increase, similar to Scenario 1. The adaptation will consider the implementation of the use of irrigation water conservation mechanisms. Water-saving mechanism will potentially save water utilization in the arid regions of Northwest China. The water consumption will only increase by 5 and $8 \%$ in the 2030s and 2050s, respectively.

Results indicate that the vulnerability of water resources in arid regions will be significantly reduced in both Scenario 1 and Scenario 2 (Fig. 14). The increase in precipitation will reduce the drought conditions and increase the amount of available water. In Scenario 2, water-saving mechanisms will reduce water consumption for agricultural use compared with Scenario 1. These situations will reduce the exposure of water resources to drought, as well as increase the amount of available water. This condition has positive implications on the adaptability of water resources. Hence, a large amount of water will be available to meet the increasing demand by the environment and ecology. Likewise, the vulnerability of water resources will consequently show a substantial decrease within these regions.

For example, in the Tarim River Basin, severe vulnerability will be significantly reduced in both scenarios, especially in the 2050s. The vulnerability value in the 2000s is evaluated to be more than 0.90 in Tarim River Basin. With the increase in precipitation, the value will be reduced to 0.87 (Scenario 1) and 0.84 (Scenario 2) in the 2030s. The ratio of ecological water consumption to basic ecological water requirements will increase to $60-70 \%$ in the 2030s. However, this value will remain insufficient to meet the ecological water needs. Vulnerability will remain severe in the Tarim River Basin. In the 2050s, vulnerability values will be reduced to 0.79 in Scenario 1 and 0.71 in Scenario 2. Water resources in the rivers in the Qaidam 
Basin, the Qinhai Lake Basin, the Inner Mongolia, and the north of Kunlun Mountain will have low or medium vulnerability in the 2030s and 2050s.

Despite the increase in precipitation and reduced water consumption, rivers in the Tuha Basin and the north of the Tianshan Mountain will still present severe vulnerability for both scenarios, because of the extremely low adaptability of water resources in the two basins. Water exploitation ratio will also remain greater than $100 \%$ in these areas. Thus, adaptive measures should be implemented immediately in these river basins to reduce vulnerability.

\section{Conclusion}

This paper is focused on two major issues: (1) the decadal climate change and water resources variability and (2) the vulnerability of water resources in the arid regions of Northwest China. Vulnerability of water resources was evaluated as a function of exposure, sensitivity, and adaptive capacity.

Results showed that the precipitation and water resources (both surface water resources and ground water recharge) exhibited significantly increasing trends after the 1980s in most parts of the arid regions of Northwest China, specifically in Xinjiang Province. However, in the rivers of Hexi Corridor and the Inner Mongolia, precipitation and water resources slightly changed over the past five decades. Water consumption and groundwater abstraction exhibited a substantial increase after the 1980s in the rivers of Hexi Corridor, the Tuha Basin, and the north of the Tianshan Mountain. In the 2000s, the water consumption has been close to or even higher than the total water resources, and the groundwater resource abstraction has exceeded the exploitable volumes within these river basins.

The exposure of water resources to drought in the arid regions decreased from the 1960 s to 2000s. The sensitivity of water resource response to precipitation changes varied among regions. Water resources were the most sensitive to precipitation variability in the river basins of Hexi Corridor and Inner Mongolia. A $10 \%$ change in precipitation will result in a 15-20\% change in water resources within the two river basins.

In most parts of the arid regions of Northwest China, water resources were evaluated with low adaptability and high or severe vulnerability in the 2000s. Water resources in Tarim Basin, Tuha Basin, Hexi Corridor, and the north of Tianshan Mountain showed severe vulnerability. Based on the CMIP5 model simulation, the precipitation will increase significantly under the RCP2.6, RCP4.5, and RCP8.5 scenarios in the future, specifically under the RCP8.5 scenario. Water vulnerability will be reduced significantly as the precipitation increases. Based on Scenario 2, the average precipitation will increase by $26.5 \%$ under the RCP8.5 scenario, and water-saving mechanisms will be enhanced in the 2050s. Vulnerability of water resources in Tarim River Basin will be substantially reduced, and water resources in the inner Mongolia, the Qaidam Basin, and the Hexi Corridor will be reduced to medium or low vulnerability. However, water resources in the Tuha Basin and the north of the Tianshan Mountain will remain severely vulnerable. Therefore, adaptive measures that can help reduce vulnerabilities of the water resources and better facilitate sustainable water resources management must be implemented within these areas.

Acknowledgments This work was supported by the National Program on Key Basic Research Project (973 Program, 2012CB956204/ 2010CB428406). We acknowledge the modelling groups for providing their data for analysis, the Program for Climate Model Diagnosis and Intercomparison (PCMDI) and the World Climate Research Programme's (WCRP's) Coupled Model Intercomparison Project for collecting and archiving the model output, organizing the model data analysis activity. The data has been collected analyzed, and are provided by National Climate Center.

\section{References}

Adger N, Aggarwal P, Agrawala S, Alcamo J, Allali A, Anisimov O, Arnell N, Boko M et al (2007) Climate change 2007: impacts, adaptation and vulnerability: working group II contribution to the fourth assessment report of the ipcc intergovernmental panel on climate change. Cambridge University Press, Cambridge

Arnell NW (1999) Climate change and global water resources. Glob Environ Chang 9:S31-S49

Babel MS, Wahid SM (2009) Freshwater under threat: South Asiavulnerability assessment of freshwater resources to environmental change. United Nations Environment Programme and Asian Institute of Technology, Bangkok

Bao C, Fang CL (2007) Water resources constraint force on urbanization in water deficient regions: a case study of the Hexi Corridor, arid area of NW China. Ecol Econ 62(3):508-517

Brown A, Matlock MD (2011) A review of water scarcity indices and methodologies. University of Arkansas, Arkansas, USA. The Sustainability Consortium, White Paper, 106

Budyko MI, Miller DH (1974) Climate and life. Academic press, New York, p 508

Cui G, Lee S, Lee W, Chung J (2010) Vulnerability assessment of water resources to climate change using GIS. ESRI international user conference, San Diego

Deng XP, Shan L, Zhang H, Turner NC (2006) Improving agricultural water use efficiency in arid and semiarid areas of China. Agric Water Manag 80(1):23-40

Dong XN, Li XM, Jia XP, Wang YM, Jiang XH (2006) Water resources investigation in Northwest China. Yellow River Conservancy Press (in Chinese)

DonohueRJ RoderickML, McVicar TR (2011) Assessing the differences in sensitivities of runoff to changes in climatic conditions across a large basin. J Hydrol 406(3):234-244

Falkenmark M (1989) The massive water scarcity now threatening Africa: why isn't it being addressed? Ambio 112-118

FellmannT, Lankoski J (2012) FAO/OECD workshop. Red, vol 23, p 24 
FengQ ChengGD, Masao MK (2000) Trends of water resource development and utilization in arid north-west China. Environ Geol 39(8):831-838

Fu BP (1981) On the calculation of the evaporation from land surface. Chin J Atmos Sci 1:002

Füssel HM (2007) Vulnerability: a generally applicable conceptual framework for climate change research. Glob Environ Chang 17(2): 155-167

Heltberg R, Bonch-Osmolovskiy M (2011) Mapping vulnerability to climate change. World Bank Policy Research Working Paper Series

Liu CZ (2003) The vulnerability of water resources in Northwest China. J Glaciol Geocryol 25(6):309-314

Ma Z, Fu C (2006) Some evidence of drying trend over northern China from 1951 to 2004. Chin Sci Bull 51(23):2913-2925

Ma Z, Kang S, Zhang L, Tong L, Su X (2008) Analysis of impacts of climate variability and human activity on streamflow for a river basin in arid region of northwest China. J Hydrol 352(3):239249

Mansur S, Rahman Y (2007) Analysis on the spatial and temporal changes of population and its influencing factors in Xinjiang in the Last 50 years. Hum Geogr 6:114-120 (in Chinese)

McCaffrey SC (1992) A human right to water: domestic and international implications. Georget Int Environ Law Rev 5:1

McNabb DE (2005) Public utilities: management challenges for the 21st century. Edward Elgar Publishing
Smit B, Pilifosova O (2003) Adaptation to climate change in the context of sustainable development and equity. Sustain Dev 8(9):9

Smit B, Wandel J (2006) Adaptation, adaptive capacity and vulnerability. Glob Environ Change 16(3):282-292

Sullivan CA, Huntingford C (2009) Water resources, climate change and human vulnerability. Paper presented at the 18th World IMACS/MODSIM Congress, Cairns/Australia

Vörösmarty CJ, Green P, Salisbury J, Lammers RB (2000) Global water resources: vulnerability from climate change and population growth. Science 289(5477):284

Wang G, Cheng G (2000) The characteristics of water resources and the changes of the hydrological process and environment in the arid zone of Northwest China. Environ Geol 39(7):783-790

Watson RT, Zinyowera MC, Moss RH (1998) The regional impacts of climate change: an assessment of vulnerability. Cambridge University Press, Cambridge

Xia J, Chen YD (2001) Water problems and opportunities in the hydrological sciences in China. Hydrol Sci J 46(6):907-921

Xiao SJ, Li QJ, Liu ZS, Wang HJ (2011) Water demand prediction of social and economic development of the river regions in the Northwest China. Yellow River 33(11):77-80 (in Chinese)

Zhang Y, Zhang S, Xia J, Hua D (2013) Temporal and spatial variation of the main water balance components in the three rivers source region, China from 1960 to 2000. Environ Earth Sci 68(4):973-983 